\title{
Effect of temperature, relative humidity and aphid developmental stage on the efficacy of the mycoinsecticide Mycotal $(B$ against Myzus persicae
}

Article

Accepted Version

Mohammed, A. A. and Hatcher, P. E. (2016) Effect of temperature, relative humidity and aphid developmental stage on the efficacy of the mycoinsecticide Mycotal ${ }^{\circledR}$ against Myzus persicae. Biocontrol Science and Technology, 26 (10). pp. 1379-1400. ISSN 1360-0478 doi:

https://doi.org/10.1080/09583157.2016.1207219 Available at https://centaur.reading.ac.uk/66144/

It is advisable to refer to the publisher's version if you intend to cite from the work. See Guidance on citing.

To link to this article DOI: http://dx.doi.org/10.1080/09583157.2016.1207219

Publisher: Taylor and Francis

All outputs in CentAUR are protected by Intellectual Property Rights law, including copyright law. Copyright and IPR is retained by the creators or other copyright holders. Terms and conditions for use of this material are defined in the End User Agreement. 


\section{www.reading.ac.uk/centaur}

\section{CentAUR}

Central Archive at the University of Reading

Reading's research outputs online 
1 Effect of temperature, relative humidity and aphid developmental

2 stage on the efficacy of the mycoinsecticide Mycotal $^{\circledR}$ against Myzus

3 persicae

$4 \quad$ Akram A. Mohammed ${ }^{1,2} \&$ Paul E. Hatcher ${ }^{1}$

$5 \quad{ }^{1}$ School of Biological Sciences, University of Reading, Berkshire, RG6 6AU, UK

$6 \quad{ }^{2}$ Plant Protection Department, University of Kufa, Najaf, Iraq

7 Corresponding author: Akram A. Mohammed. E-mail: abodarba@yahoo.com

8 (Received 29 October, 2015; Returned 6 January; Accepted 25 June, 2016)

9

10 DOI: $10.1080 / 09583157.2016 .1207219$.

11

12

13

14 For Biocontrol Science and Technology

15

16

17 
The green peach aphid, Myzus persicae, is a major pest worldwide. An examination of the impact of temperature, relative humidity and developmental stages of $M$. persicae on the efficacy of the whitefly mycoinsecticide Mycotal ${ }^{\circledR}$, based on Lecanicillium muscarium and the effects of infection on aphid fecundity was evaluated under controlled conditions. Although this fungus can be grown at a broad range of temperatures $\left(15-30^{\circ} \mathrm{C}\right)$, the optimum temperature for control of $M$. persicae ranged between 20 and $30^{\circ}$ C. L. muscarium had high efficacy as a microbial control against $M$. persicae between 55 and $90 \%$ relative humidity. Total mortality of aphids treated with different spore dosages of L. muscarium varied according to the developmental stage: adults, fourth and third instar nymphs of proved more susceptible than first instar nymphs. Although the fungus did not affect the rate of nymph production, the reproductive period of aphids significantly decreased with increasing the spore dosage. Thus, total fecundity of treated aphids was $22.6 \pm 1.1$ and $31.6 \pm 2.4$ offspring per adult at the medium $\left(644 \pm\right.$ viable spore $\left./ \mathrm{mm}^{2}\right)$ and low $\left(330 \pm 40\right.$ viable spore $\left./ \mathrm{mm}^{2}\right)$ dosages, compared with $45.7 \pm 4.3$ offspring per untreated aphid. The results suggest that $L$. muscarium has the potential as a biological control agent of $M$. persicae. However, fungal infection appears to have no sub-lethal effects on the fitness of the host's progeny.

Keywords: temperature, relative humidity, Mycotal $^{\circledR}$, developmental stage, total fecundity, reproduction rate

\section{Introduction}

The green peach aphid, Myzus persicae Sulzer (Hemiptera: Aphidiae), is one of the most important and common aphid species of greenhouse and field crops worldwide (Blackman \& Eastop, 2007). It is highly polyphagous infesting crops in over 40 plant families (Blackman \& Eastop, 2008) causing damage by direct feeding (Saljoqi, 2009), 
the development of sooty mould on honeydew (Miller, Gubler, Laemmlen, Geng, \& Rizzo, 2004) and the transmission of over 100 plant virus diseases (Dedryver, Le Ralec, \& Fabre, 2010).

Potential biological control methods for $M$. persicae include the use of predators such as ladybird beetles (Dixon, 2000) and parasitoids (Perdikis, Lykouressis, Garantonakis, \& Iatrou, 2004). A further potential method for M. persicae biocontrol agent is the use of entomopathogenic fungi (Ashouri, Arzanian, Askary, \& Rasoulian, 2003; Xu \& Feng, 2002; Yeo, Pell, Alderson, Clark, \& Pye, 2003). Several entomopathogenic fungi, including Lecanicillium spp. (Hypocreales: Ascomycete), play an important role in biological control of aphids (Kim, Goettel, \& Gillespie, 2007). Lecanicillium spp. also have activity against many phytopathogenic fungi, including powdery mildews (Miller et al., 2004). In laboratory conditions, Lecanicillium spp. have been reported to be more virulent against aphid species when compared to Beauveria bassiana, Isaria fumosorosea and Metarhizium anisopliae (Åsman, 2007; Loureiro \& Moino Jr, 2006). Worldwide, at least two products based on Lecanicillium longisporum have been developed commercially to control aphids; Vertalec ${ }^{\circledR}$ and Vertirril WP $1300^{\circledR}$. However, in the UK, the strain of $L$. longisporum marketed as a Vertalec ${ }^{\circledR}$ is no longer commercially available (Faria \& Wraight, 2007). Little is known about the efficacy of $\operatorname{Mycotal}^{\circledR}$ (L. muscarium) which is on the UK market to control whitefly species, against M. persicae (Hall, 1982). To evaluate the potential of Mycotal ${ }^{\circledR}$ against M. persicae studies on aspects influencing the ability of this commercial formulation to control aphids are required. and colonise host insects are the effect of temperature (Yeo et al., 2003), relative humidity (Milner \& Lutton, 1986) and developmental stage of aphid host (Kim \& 
Roberts, 2012). Temperature and relative humidity can have a significant impact on the rate of infection and time to death of insects treated by affecting conidial germination, and germ tube development and penetration through the host cuticle (Shi, Feng, \& Liu, 2008). Furthermore, entomopathogenic fungi infect their host via direct penetration of the cuticle and since juvenile aphids shed their cuticle in the moulting process at relatively short intervals (about 2 days) (Diaz \& Fereres, 2005) juveniles may thereby reduce their susceptibility to fungal infection compared to adults. The differences may also be related to cuticle biochemical composition, physiological characteristics and/or method of fungal application, as shown for other arthropods (Kirkland, Cho, \& Keyhani, 2004; Tang \& Hou, 1998).

Another important aspect is the effect of the pathogen infection on the rate of nymph production and the length of reproductive time of aphids. Studies by $\mathrm{Xu} \&$ Feng (2002), Baverstock, Roy, Clark, Alderson, \& Pell, ( 2006), Roditakis, Couzin, Franks, \& Charnley, (2008), Gurulingappa, McGee, \& Sword, (2011) and Shrestha, Enkegaard, \& Steenberg, (2015) have reported significant reductions in reproduction rate and the reproductive period after treatment with entomopathogenic fungi. Reduction in the rate of nymph production by a fungus-infected host could be attributed to histological and cytological injuries to the ovaries, thus affecting follicle development or causing their degeneration (Sikura, Sikura, \& Trebesava, 1972). Infection by entomopathogenic fungi can also result in reduced food intake in aphids, which could be a contributory factor in the drop in reproductive rate (Roditakis et al., 2008). Competition with the fungus for host resources and a negative impact of the fungus on host physiology such as through tissue invasion or production of toxic metabolites, may also important in reducing the reproductive output (Furlong, Pell, \& Reddy, 1997). 
relation to the green peach aphid. Such information may help us predict the ability of $\left(\right.$ Mycotal $\left.^{\circledR}\right)$ to reduce the aphid population level in the field and glasshouse under realistic conditions. This study therefore aimed to investigate (1) the efficacy of the commercial mycoinsecticide $\left(\mathrm{Mycotal}^{\circledR}\right)$ against $M$. persicae at different regimes of temperatures and humidity, (2) the susceptibility of different instar nymphs and adults of $M$. persicae to this product, (3) the effects of fungal infection on the fecundity of individual aphids and aphid population growth and (4) the effects of fungal infection on the maturation time and the rate of nymph production of the host aphid's progeny.

\section{Materials and methods}

\subsection{Plant material}

Brussel sprouts, Brassica oleracea var. gemmifera L. cultivar Bedford-Winter Harvest (Suttons Seeds, Paignton, UK) were established for the M. persicae cultures and for the experimental work. This cultivar has been identified as $M$. persicae susceptible (Qayyum, 1999), and ensured a regular supply of large numbers of aphids throughout the year. Loam-based potting compost (John Innes No. 2: Roffey Brothers, Bournemouth, UK) was used.

\subsection{Rearing M. persicae}

The green peach aphid, M. persicae, was collected initially from cabbage plants in the experimental garden at the University of Reading, in 2013. The aphids were identified under a light compound microscope, using both cabbage aphid and polyphagous aphid keys (Blackman \& Eastop, 2000). Myzus persicae was reared on Brussels sprouts plants 5-6-weeks old in $45 \times 45 \times 45 \mathrm{~cm}$ cages at $21 \pm 2^{\circ} \mathrm{C}$ and with $16: 8 \mathrm{~h}$ daily photoperiod for several generations. Plants were replaced every 2 weeks with healthy 5-6 week-old plants.

\subsection{Fungus application}


118 A formulation of Lecanicillium muscarium (Mycotal@ by Koppert Biological Systems,

119 Berkel en Rodenrijs, the Netherlands) (Aqueel \& Leather, 2013) was used. The product

120 is based on conidia of the KV01 strain isolated from a dead T. vaporariorum adult from

121 a glasshouse in the UK (Fargues et al., 2003). This mycoinsecticide which contains $10^{10}$

122 spore $\mathrm{g}^{-1}$ was kept at $4^{\circ} \mathrm{C}$ until use. A stock suspension was prepared by mixing $100 \mathrm{~g}$ of

123 wettable Mycotal ${ }^{\circledR}$ powder in $1000 \mathrm{ml}$ of sterile water and $0.02 \%$ Tween 80 (BDH

124 Chemicals Ltd, Poole, UK) in $2000 \mathrm{ml}$ beakers then agitating for 30 minutes on a

125 magnetic stirrer. The resulting dosage (high dosage) was either used as prepared or

126 diluted 100-fold and 10000-fold to produce the medium and low dosage, respectively.

127 The viability and density of spores for each dosage was determined using the procedure

128 described by Poprawski \& Jones (2000). 1ml of either the high, medium or low dosages

129 was sprayed on plates with $1.5 \%$ Sabouraud dextrose agar (SDA). The plates were

130 sealed with parafilm and incubated at $20^{\circ} \mathrm{C}, 90 \pm 2 \% \mathrm{RH}$ and a photoperiod of $16: 8 \mathrm{~h}$

131 (L:D). After 24h, four $0.05 \mathrm{~mm}^{2}$ microscope fields (400× magnification) observed on

132 each plate, the number of germinated and non-germinated spores was counted and

133 counts were averaged per $1 \mathrm{~mm}^{2}$. The plates treatments were replicated 5 times for each

134 dosage. Germination was considered positive when the length of germ tube was at least

135 half of the spore length. The dosage of spores that the aphids received in each treatment

136 was evaluated by counting the number of viable spores per $\mathrm{mm}^{2}$. The mean number \pm

137 standard error of high, medium and low dosages for L. muscarium were $880 \pm 32,644 \pm$

13850 and $330 \pm 40$ viable spore $/ \mathrm{mm}^{2}$, respectively. The viability of the L. muscarium

139 spores used in the bioassays exceeded $89 \%$.

140 For each treatment, $1 \mathrm{ml}$ of spraying suspension was applied once on each leaf

141 containing aphids, using a $750 \mathrm{ml}$ trigger water sprayer (Ampulla, Hyde, UK). The 
application was made with a distance of $15 \mathrm{~cm}$ between the sprayer nozzle and plant leaf, to ensure that the fungal application covered the whole leaf and all aphids.

\subsection{Production of known-age third instar nymphs of M. persicae}

In order to obtain a uniform age of third instar nymphs of $M$. persicae for use in all experiments, adults were transferred from stock culture onto 6-week-old Brussels sprouts plants (20 adults per plant) using two 3-cm-diameter clip cages and allowed to produce nymphs for 1 day in a growth chamber at $20^{\circ} \mathrm{C}, 75 \pm 2 \% \mathrm{RH}$ and a photoperiod of 16:8 $\mathrm{h}(\mathrm{L}: \mathrm{D})$. The adults were then removed and the offspring counted (50 nymphs per plant) and allowed to develop on the plants for 4 additional days before each experiment. If the number of nymphs was less than 50 per plant, the adults were kept on the leaves for another day until they produced 50 nymphs.

\subsection{Effect of relative humidity $(R H)$ on L. muscarium efficacy}

Two laboratory experiments were carried out on different dates to determine the effect of relative humidity on the efficacy of $L$. muscarium against third instar nymphs . In both experiments a uniform age of aphid nymphs (4-5 days old) was obtained as treated plants in the growth chambers at 55 and $90 \%$ relative humidity were transferred to the growth chamber at $70 \% \mathrm{RH}$ for 8 days. This relative humidity level was based on the average daily high, moderate and low relative humidities in the field in the UK 
167 (Climatological station, 2013). Relative humidity within the experimental growth 168 chambers remained relatively stable and never varied more than $4 \%$ from the target 169 humidity while chambers were sealed. To prevent aphids moving between treated 170 plants, they were kept in the 3-cm-diameter clip-cages post spraying. To minimize the

171 impact of horizontal transmission caused by spores discharged from cadavers killed 172 with L. muscarium on estimation of the efficacy of L. muscarium, the dead aphids were removed daily for 10 days. Dead aphids were surface sterilised by rinsing twice with $70 \%$ ethanol for 30 seconds and then with sterilised distilled water and thereafter placed on water agar ( $3 \mathrm{~g}$ of agar $\mathrm{L}^{-1}$ of water) in Petri dishes for 5 days, to confirm infection by L. muscarium (Aiuchi et al., 2012). A cadaver was regarded as having died from infection by this fungus if conidia of L. muscarium were recovered from it. The second experiment repeated the procedure of the first experiment, except that after spending 2 days at 55,70 or $90 \% \mathrm{RH}$ the treated plants were transferred to a growth chamber at $55 \%$ RH for 8 days. This relative humidity (55\%) was used because it has been recorded as a lower average RH in the field in the UK (Climatological station, 2013). The experiments were repeated once on a different date.

\subsection{Effect of temperatures on L. muscarium efficacy}

Two laboratory experiments were carried out on different dates to determine the effect of temperature on the efficacy of L. muscarium against third instar nymphs. In both experiments, a uniform age of aphid nymphs (4-5 days old) was obtained as described above. The high, medium and low spore dosages of $\mathrm{Mycota}^{\circledR}{ }^{\circledR}$ were each sprayed onto sprayed with $0.02 \%$ sterile aqueous Tween 80 only. After treatment, the plants were kept at room temperature for $1 \mathrm{~h}$ to dry. 
In the first experiment, the treated plants were arranged in four groups (five

192

plants per spore dosage and control), and then each transferred to one of four different plant growth chambers (Fitotron-Weiss Technik Ltd, Leicestershire, UK) at $75 \pm 2 \%$ $\mathrm{RH}$, a photoperiod of 16:8 $\mathrm{h}(\mathrm{L}: \mathrm{D})$ and one of the following temperatures: 15, 20, 25, or $30^{\circ} \mathrm{C}$ for 10 days. These temperatures were chosen to represent an average daily low and high temperature experienced under summer field conditions in the UK. To prevent aphids moving between treated plants, the aphids were kept in the 3-cm-diameter clipcages post-spraying. Dead aphids were counted and removed daily for a period of 10 days at each temperature. The method described in section 2.5 was used to confirm infection by L. muscarium.

The second experiment followed the method described in the first experiment above, except that treated plants were placed in four growth chambers at $75 \pm 2 \% \mathrm{RH}$, a photoperiod of $16: 8 \mathrm{~h}(\mathrm{~L}: \mathrm{D})$ and one of the following temperatures: $15,20,25$, or $30^{\circ} \mathrm{C}$ for 3 days. Subsequently, all plants were transferred to a plant growth chamber at $20^{\circ} \mathrm{C}$ for 7 days. The experiments were repeated once on a different date.

\subsection{Effect of aphid developmental stages on the efficacy of L. muscarium}

This experiment was carried out under controlled conditions in a growth chamber (Sanyo, Gallenkamp, UK) at $20^{\circ} \mathrm{C}, 75 \pm 2 \% \mathrm{RH}$ and a photoperiod of 16:8 h (L:D). In order to obtain a uniform age of different developmental stages of M. persicae (adults, $4^{\text {th }}$ instars, $3^{\text {rd }}$ instars and $1^{\text {st }}$ instars), adults were transferred from a stock culture of $M$. persicae onto 6-week-old Brussel sprouts plants (20 adults per plant) using two 3-cmdiameter clip-cages and allowed to produce nymphs for 10, 7, 5 or 1 days before bioassay to allow all four developmental stages to be available for experimental use on the same treatment date. The adults were then removed and the offspring counted (50 nymphs per plant) and allowed to develop on the plants for 9, 6, 4 or 0 additional days 
216 before beginning the experiment in the growth chamber at $20^{\circ} \mathrm{C}, 75 \pm 2 \% \mathrm{RH}$ and a photoperiod of 16:8 (L:D) h.

The high, medium and low spore dosages of Mycotal $^{\circledR}$ were each sprayed onto

Brussels sprouts plants which had either 50 first instar nymphs, third instar nymphs, fourth instar nymphs or adults. The control group was sprayed with $0.02 \%$ sterile aqueous Tween 80 only. After treatment, the plants were kept at room temperature for 1 $\mathrm{h}$ to dry and then returned to the same growth chamber with conditions as described above. Dead aphids were counted and removed daily for a period of 10 days post spraying. The method described in section 2.5 was used to confirm infection by $L$. muscarium. For each aphid developmental stage, five replicates were carried out at each spore dosage and for the control. This experiment was repeated in the same growth chamber on a different date.

\subsection{Effect of L. muscarium infection on individual aphids and their progenies}

This experiment was carried out to determine the effect of fungal infection on the rate of nymph production and the length of reproductive time of aphids. The method described in section 2.7 was used to obtain a uniform age of adult, $3^{\text {rd }}$ and $1^{\text {st }}$ instar nymphs. The medium and low spore dosages of Mycotal $^{\circledR}$ were each sprayed once onto infested leaves of Brussel sprouts plants which had either 50 first instar nymphs, third instar nymphs or adults. Control treatments were sprayed with $0.02 \%$ sterile aqueous Tween 80 only. After fungal treatment, the plants were kept at room temperature for $1 \mathrm{~h}$ to dry and then transferred to the same growth chamber under the same conditions described above for 1 day. After this period a single exposed aphid which had been inoculated with either of the treatments or control was selected randomly and transferred (20 individuals of each aphid stage per treatment) with a fine camel hair brush onto healthy Brussel sprouts plants using 2-cm-diameter clip-cages. Plants were then transferred to 
the same growth chamber in the same conditions described above. Each leaf clip cage was carefully opened and inspected daily until death and mortality and nymph production by each individual were recorded. And all offspring and dead aphids were removed. The method described in the relative humidity assays was used to confirm infection by L. muscarium. Offspring of fungus-treated third and first instar nymphs were also counted when they reached adult stage and started reproducing. To determine the effect of fungal infection on the number of nymphs produced from the progeny of infected aphids, offspring of fungus-treated and untreated adults (20 first instar nymphs per treatment which were obtained from above experiment) were selected randomly and transferred individually with a fine camel hair brush onto healthy Brussel sprouts plants and contained in a 2-cm-diameter clip-cage in the plant growth chamber at $20^{\circ} \mathrm{C}, 75 \pm 2 \% \mathrm{RH}$ and a photoperiod of $16: 8 \mathrm{~h}(\mathrm{~L}: \mathrm{D})$. They were allowed to develop on the plants until they became adults and started reproducing. The number of nymphs produced by these first generation adults was recorded daily for the number of days equal to the length of the aphid's development period (birth until first uniform age of adult aphids. Ninety-six Brussels sprouts plants (6-7 weeks old) were 
cages for 1 day. After this period, the clip-cages were removed and three treatments each with 32 plants were used, one treatment received $1 \mathrm{ml}$ of the medium dosage (644 \pm 50 viable spore $/ \mathrm{mm}^{2}$ ) per plant, one received $1 \mathrm{ml}$ of the low dosage $(330 \pm 40$ viable spore $/ \mathrm{mm}^{2}$ ) per plant and one was a control and only sprayed with $0.02 \%$ sterile aqueous Tween 80 . After treatment, the plants were kept at $21 \pm 2^{\circ} \mathrm{C}$ for 1 hour to dry. To prevent aphids from escaping, the plants were covered individually with perforated plastic bags (Al-Naemi \& Hatcher, 2013). They were then transferred to the growth chamber at $20^{\circ} \mathrm{C}, 75 \pm 2 \% \mathrm{RH}$, a photoperiod of $16: 8 \mathrm{~h}(\mathrm{~L}: \mathrm{D})$ and at 2, 3, 4 and 5 weeks after fungal treatment a subset of 8 plants of each treatment were randomly selected and destructively harvested, removing all aphids. All plants (only the shoots) were dried at $80^{\circ} \mathrm{C}$ for 2 days to constant weight and weighed. Population growth rate was calculated using the formula population growth rate $=\left(\mathrm{N}_{\mathrm{t}}-\mathrm{N}_{0}\right) /\left(\mathrm{t}-\mathrm{t}_{0}\right)$, where $\mathrm{N}_{\mathrm{t}}$ is the number at time $t, \mathrm{~N}_{0}$ is the initial number, and $\mathrm{t}_{0}$ is the initial time (Pianka, 2011). The experiment was repeated once on a different date.

\subsection{Statistical analysis}

Statistical analyses were conducted using GenStat (version 16; VSN International, Hemel Hempstead, UK). Normality of data distribution was estimated using a ShapiroWilk test (W-test). The data were transformed using arcsine square-root when it was necessary to meet the assumption of normality. The effect of temperature, relative humidity and developmental stages were assessed by repeated measures analyses of variance. Two-way ANOVA was used to compare between two laboratory experiments to determine the effect of relative humidity. Aphid mortality was corrected for natural death in the control using Abbott's formula (1925), which calculates the proportion of aphids killed by the fungus alone. The total fecundity data for individual aphids treated with two different dosages of L. muscarium and their progenies were analysed 
separately by two-way ANOVA. Unbalanced repeated measurements ANOVA was used to determine the effect of fungal application on the rate of nymph production per day because the high spore dosage $\left(880 \pm 32\right.$ viable spore $\left./ \mathrm{mm}^{2}\right)$ caused $100 \%$ mortality after 10 days of treatment compared to low conidial concentration and control. Repeatmeasurements ANOVA was used to determine the effect of fungal application on the population size and dry weight of plants 2, 3, 4, and 5 weeks after application, compared to untreated plants. Mean comparisons were performed using LSD test at 5\% level of significance $(P<0.05)$.

\section{Results}

\subsection{Effect of relative humidity (RH) on L. muscarium efficacy}

In the first experiment, aphid mortalities caused by the same conidial concentration when placed at 55,70 or $90 \%$ RH for 2 days and then 8 days at $70 \% \mathrm{RH}$ were not significantly different $\left(F_{2,436}=1.33, P=0.265\right)$, with the highest corrected mortality (100\%) caused by the high dosage (880 viable spore/ $\mathrm{mm}^{2}$ ) of L. muscarium after 6 days in all treatments. The medium (644 viable spore $/ \mathrm{mm}^{2}$ ) and low (330 viable spore $/ \mathrm{mm}^{2}$ ) dosages were also effective but required longer to achieve a high level of aphid mortality in comparison (Figure 1). The interaction between relative humidity, spore dosage and time after application was also not significant $(P>0.05)$. Aphid mortality in control treatments ranged between 5.6 and $8 \%$.

In the second experiment, aphid mortalities when subjected to 55,70 or $90 \% \mathrm{RH}$ for 2 days and then 8 days at $55 \% \mathrm{RH}$, were not significantly different $\left(F_{2,452}=2.17, P\right.$ $=0.115)$ at any of the tested spore dosages, with the highest level of corrected mortality (100\%) caused by a high dosage of $L$. muscarium after 8 days in all RH treatments. The medium and low spore dosages were also effective, but required a longer period of time to achieve a high level of aphid mortality (Figure 2). The interaction between relative 
humidity, spore dosage and time after fungal application was also not significant $(P>$ 0.05). Aphid mortality in control treatments ranged between 4 and $7.6 \%$.

The level of aphid mortality was not significantly different between the two experiments $\left(F_{1,1108}=0.06, P=0.814\right)$, and the period of time required to achieve a high level of aphid death was also not significantly different between the two experiments for each spore dosage $\left(F_{1,1108}=0.24, P=0.626\right)$.

\subsection{Effect of temperatures on L. muscarium efficacy}

In the first experiment, results indicated that temperature had a significant effect on the aphid corrected mortality caused by $L$. muscarium 10 days post-spraying $\left(F_{3,600}=\right.$ 1633.03, $P \leq 0.001$ ), with the lowest mortality found in aphids incubated at $15^{\circ} \mathrm{C}$

(Figure 3). The effect of spore dosage of L. muscarium and time after application on the percentage of aphid corrected mortality was significant $(P \leq 0.001)$, with $100 \%$ mortality recorded for aphids treated with the high dosage (880 viable spore $/ \mathrm{mm}^{2}$ ) and incubated at 20,25 and $30^{\circ} \mathrm{C} 6$ days after treatment. The interactions between temperature, fungus concentration and time after application were significantly different $(P \leq 0.001)$. Aphid mortality in control treatments ranged between 3 and $6 \%$.

Results of the second experiment showed that incubation of fungus-treated aphids at different temperatures for 3 days and then 7 days at $20^{\circ} \mathrm{C}$ had a significant effect on the period of time required to obtain a high level of aphid mortality $\left(F_{3,596}=\right.$ $311.97, P \leq 0.001)$. For instance, $100 \%$ aphid mortality occurred 6 days after treatment with the high dosage ( 880 viable spore $/ \mathrm{mm}^{2}$ ) when aphids were incubated at 25 or $30^{\circ} \mathrm{C}$ for 3 days and then at $20^{\circ} \mathrm{C}$ for 10 days., This was 3 days earlier compared with aphids incubated for 3 days at $15^{\circ} \mathrm{C}$ and at $20^{\circ} \mathrm{C}$ afterward (Figure 4). The interactions between temperature, spore dosage and time after application were significantly different $(P \leq$ 0.001). Aphid mortality in control treatments ranged between 2 and $7 \%$. 


\subsection{Effect of aphid developmental stages on the efficacy of L. muscarium}

342 The developmental stage of $M$. persicae had a significant effect on the aphid corrected mortality when aphids were treated with either high, medium or low dosages of $L$. muscarium, with the highest mortality to adults, $4^{\text {th }}$ instars and $3^{\text {rd }}$ instars, compared with $1^{\text {st }}$ instars 10 days post-spraying $\left(F_{3,572}=348.27, P \leq 0.001\right)$ (Figure 5$)$. Spore dosage had a significant effect on aphid mortality at each aphid developmental stage, with the highest mortality occurring at the high dosage (880 viable spore/mm²). Aphid mortality was much lower in control treatments and ranged from 3 to $7.2 \%$.

\subsection{Effect of L. muscarium infection on fecundity of individual aphids and their}

progenies

There was no significant effect of treatment on the rate of nymph production when $L$. muscarium was sprayed on $1^{\text {st }}$ instar nymphs, $3^{\text {rd }}$ instar nymphs and adults, compared to the control (fungal concentration: $F_{2,134}=2.07, P=0.211$; exposed stage: $F_{2,134}=1.22$ $P=0.299)$. However, the reproductive period of aphids significantly decreased with increasing the number of viable spores per $\mathrm{mm}^{2}$ of $L$. muscarium $\left(F_{2,134}=133.17, P \leq\right.$ $0.001)$. The total fecundity of aphids differed significantly among spore dosages of $L$. muscarium $\left(F_{2,179}=41.89 ; P \leq 0.001\right)$, with the lowest fecundity found in those aphids treated with the medium dosage (644 viable spore $/ \mathrm{mm}^{2}$ ) (Figure 6). Aphid developmental stage at the time of exposure showed a significant effect on the total fecundity of aphids $\left(F_{2,179}=4.63 ; P \leq 0.001\right)$ and the interaction between aphid developmental stage and spore dosage of L. muscarium as factors affecting the total fecundity of infected aphids was not significantly different $(P \leq 0.001)$.

Maturation time of progenies produced from fungus-treated aphids at different stages was $9.1 \pm 0.4$ days, but not significantly different compared to progenies produced from untreated aphids $\left(F_{2,175}=0.59, P=0.557\right)$, The rate of nymph 
production of the progenies of fungus-treated and untreated aphids was $3.4 \pm 0.3$ nymphs, but not significantly different compared to progenies produced from untreated aphids $\left(F_{2,89}=0.18, P=0.832\right)$. The mean fecundity did not differ between progeny of fungus-treated aphids and untreated aphids $\left(F_{2,179}=0.30, P=0.738\right)$.

\subsection{Effect of L. muscarium on aphid populations}

Aphid colonies treated with L. muscarium were significantly smaller than those of the control, with untreated plants having 5 fold more aphids than the aphid colonies treated with the medium dosage (644 viable spore/ $\mathrm{mm}^{2}$ ) (Table 1 and Figure 7A). In all treatments, the number of aphids varied significantly during the time post-treatment, with the highest number of aphids recorded 5 weeks post treatment and the interaction between treatments and the time after treatments were also significantly different $(P \leq$ 0.001). The rate for the increase of the aphid population depended on both spore dosage and the time after fungal treatment (Table 2). The results indicated that shoot dry weight of untreated plants was reduced by about $30 \%$ compared with plants treated with the fungus at the medium dosage during the time after application (Table 1 and Figure 7B).

\section{Discussion}

\subsection{Effect of temperature, relative humidity and aphid developmental stage on the} efficacy of L. muscarium

Most of the published efficacy data for this commercial product relate to control of whiteflies. Cuthbertson \& Walters (2005) reported that the application of Mycotal ${ }^{\circledR}$ against sweet-potato whitefly Bemisia tabaci under laboratory conditions resulted in 90\% mortality after 7 days. In addition, Fatiha, Ali, Ren, \& Afzal (2007) reported that the mortality caused by different isolates of $L$. muscarium against third instar of $B$. tabaci varied between 87 and $56 \%$ after 8 days. The present study has shown that the application of $\mathrm{Mycotal}^{\circledR}$, against $M$. persicae within the laboratory resulted in a high 
level of mortality and it shows potential as an important biological control agent of $M$.

392

393

394

395

396

397

398

399

400

401

402

403

404

405

406

407

408

409

410

411

412

413

414

415

persicae.

Constant temperature had a significant effect on the efficacy of the fungus $L$.

muscarium, with, however, the highest efficacy and infection occurring in a broad

temperature range $\left(20-30^{\circ} \mathrm{C}\right)$ (Figure 3 ). Similarly to our results, Vu, Hong, \& Kim

(2007) found that $V$. lecanii caused the highest mortality of $M$. persicae in the same,

broad temperature range $\left(20-30^{\circ} \mathrm{C}\right)$. Sharififard, Mossadegh, \& Vazirianzadeh (2012)

found that the efficacy of B. bassiana and M. anisopliae were also higher in the same,

broad temperature range $\left(20-30^{\circ} \mathrm{C}\right)$ and that the $\mathrm{LT}_{50}$ values reflected this finding,

decreasing when temperature varied between $20-30^{\circ} \mathrm{C}$. High numbers of fungus-

infected aphids and the ability of the fungus to kill aphids quickly in a broad

temperature range $\left(20-30^{\circ} \mathrm{C}\right)$ may be related to the ability of $L$. muscarium to germinate and colonise aphids rapidly (Yeo et al., 2003).

Laboratory bioassays under alternating temperature showed that although

incubation at a lower temperature $\left(15^{\circ} \mathrm{C}\right)$ for 3 days caused a significant reduction in the efficacy of L. muscarium against aphids, the aphid mortality occurred as quickly when the treated plants were transferred at $20^{\circ} \mathrm{C}$ (Figure 4). This may be explained by lower conidia germination and/or increasing the death rate of fungal conidia at $15^{\circ} \mathrm{C}$. There are few studies that have investigated the effect of fluctuating temperatures on the efficacy of entomopathogenic fungi on aphids. Feng, Poprawski, Nowierski, \& Zeng (1999) found that the efficacy of Pandora neoaphidis against the pea aphid Acyrthosiphon pisum was greater at a constant temperature $\left(20^{\circ} \mathrm{C}\right)$ than at alternating temperatures $\left(5 \cdot 5-18.9^{\circ} \mathrm{C}\right)$. Although we did not investigate the effect of daily fluctuating temperature, trials of the effect of fluctuating temperatures on the efficacy of entomopathogenic fungi could be more useful and accurate than constant temperatures 
in predicting the efficacy and speed of kill of L. muscarium against M. persicae under glasshouse or field conditions, as they may be more representative of the conditions that L. muscarium will be exposed to in actual crop conditions. corrected mortality of aphids caused by L. muscarium or the speed of death (Figure 1 and Figure 2). This may be due to the fact that relative humidity may not be the same as the humidity in the microenvironment immediately next to the insect or leaf surface (Willmer, 1986). Wraight et al. (2000) reported that the insect host and leaf substrate together contribute to create a zone of high humidity that supports germination, colonisation and sporulation of entomopathogenic fungi. These results confirmed the findings of other researchers (Doberski, 1981; Ferron, 1977) who demonstrated that infection of some pest species by entomopathogenic fungi may occur at low as well as high relative humidities (30 to 75\%). Contrary to the findings of these authors, and those of this study, Hsiao, Bidochka, \& Khachatourians (1992) reported that when relative humidity was reduced for a period of time, some isolates of Lecanicillium spp. had lower levels of efficacy. Milner \& Lutton (1986) also reported that conidia of $L$. lecanii required $100 \%$ relative humidity for at least 3 days before removal to $70 \%$ humidity to obtain about $90 \%$ mortality of $M$. persicae. Sukhova (1987), tested different isolates of $V$. lecanii and $B$. bassiana against whitefly populations and also reported high relative humidity (80-90\%) was required to achieve $100 \%$ mortality of whitefly. The differences between the findings of these previous studies and the experiments detailed here may be due to differences in the bioassay procedures, target insect pests and/ or whether conidia or blastospores were used as the inoculum. 
441 (adults, fourth instar nymphs and third instar nymphs). Moreover, the corrected mortality in all aphid developmental stages was dependent on fungal dose, with the highest mortality occurring at the high dosage (880 viable spore $/ \mathrm{mm}^{2}$ ) (Figure 5). These results are in agreement with previous studies including lower mortality caused by different conidial concentrations of L. attenuatum in first instar nymphs of A. gossypii as compared with other developmental stages reported by Kim \& Roberts (2012). The lower susceptibility of young instars of insects to infection by entomopathogenic fungi has been reported to be related to fast and frequent moulting ( Kim \& Roberts, 2012; Wekesa, Knapp, Maniania, \& Boga, 2006), which may be explained by changes in cuticle biochemical composition during development such as the presence of toxic compounds which may inhibit spore germination (Kirkland et al., 2004), or low numbers of spores attaching to the cuticle of early instar nymphs as a result of their small body size (Tang \& Hou, 1998). We suggest that the lower fungus-mortality of first instar nymphs of $M$. persicae may be due to multiple moulting (within about 2 days after fungal application) causing fewer spores to adhere to the new cuticle, perhaps also in association with a low germination percentage on the cuticles of first instar nymphs. Decreased conidial adhesion was observed by Kim \& Roberts (2012), who reported that the number of fungal conidia adhering to cuticles of young instar nymphs of A. gossypii declined with increasing time after treatment due to moulting. In addition, the smaller body size of first instar nymphs may have played a role in the lower infection with $L$. muscarium by proportionate decline of the conidial load.

\subsection{Effect of fungal infection on individual life history and on population} development of M. persicae

464 The main objective of these studies was to gain information on the role played by $L$. muscarium on the daily fecundity, total fecundity, development time and $r_{m}$ value of 
466 fungus-treated aphids and their progenies. These results led to the rejection of the hypotheses that individuals of $M$. persicae treated with $L$. muscarium produce nymphs at a different rate compared to untreated aphids and that offspring produced by fungustreated aphids have a high chance of acquiring the fungus before birth. Although the pathogen had a significant effect on overall aphid fecundity, this effect was caused by increasing aphid mortality which resulted in reducing the length of reproductive time of fungus-treated aphids (Figure 6). The fact that fungal infection has no negative effect on the rate of nymph production per day may be a result of the host diverting resources to defence and then reproduction as a strategy to increase fitness. Furthermore, the selection pressure of generalist hypocrealean fungi like L. muscarium may be too weak to modify the behaviour of the aphids, compared to host-specific entomopathogenic fungi like Pandora neoaphidis (Roy, Baverstock, Chamberlain, \& Pell, 2005). The results obtained in the present study are consistent with Wang \& Knudsen (1993) and Kim (2007) who reported that daily fecundity of individual aphids did not decrease due to fungal treatment but total fecundity significantly decreased due to increasing level of aphid mortality rather than by differential reproduction rates of individuals. However, indirect effects of entomopathogenic fungi on aphid reproduction seem to depend on aphid species and/or the fungal species or isolate. Thus, Askary, Carriere, Belanger, \& Brodeur (1998) found a negative impact on reproduction of potato aphids Macrosiphum euphorbiae treated with Vertalec ${ }^{\circledR}$ and Shrestha et al. (2015) found a negative effect on the daily rate of nymph production of $N$. ribisnigri treated with either high, medium or low conidial concentrations of B. bassiana. mother is still an embryo. Consequently, the embryos inside an adult parthenogenetic 
aphid carry embryos themselves. This so-called telescoping of generations which is a major reason for the high intrinsic rate of increase in aphid populations and the agricultural harm that they can cause (Kindlmann \& Dixon, 1989) as this reproductive strategy gives aphids approximately a threefold reproductive advantage (Dixon, 1990). Thus, it might be expected that fungal infection would have an impact on fecundity beyond the first generation of offspring. However, our results showed that fungal infection of aphids has no negative effects on their progenies' mean development time, total fecundity and $\mathrm{r}_{\mathrm{m}}$-value. Fungal infection, therefore, appears to affect the host aphid's reproduction numerically but does not have a physiological effect on the developing progeny. These results were in agreement with Baverstock et al. (2006) who reported that the intrinsic rate of increase did not differ between progeny of fungusinfected aphids and uninfected aphids when they were infected by either $P$. neoaphidis or B. bassiana.

The aphids' population was significantly affected by L. muscarium infection. The results showed that the aphid population exposed to the medium spore dosage (644 viable spore $/ \mathrm{mm}^{2}$ ), resulted in a significantly much smaller population size than the unexposed population (Figure 7A). The significant reduction in the population size of treated aphids was most likely to be caused by the impact of fungus treatment on the total fecundity of individual aphids as a result of a higher mortality rate or that nymph may become infected, once in contact with fungus-sporulation aphids. However, spraying the fungus only once was not sufficient to achieve a good level of control as the economic threshold level of $M$. persicae on Chinese cabbage was calculated to be 20 aphids per plant (Jeon, Kang, Kim, Yang, \& Kim, 2008). This is in line with data of Xu $\&$ Feng (2002) who report that the size of an aphid population contaminated with $P$. 
515 delphacis at a concentration of $112 \pm 22.8$ conidia $/ \mathrm{mm}^{2}$ was significantly smaller than

516 those of the controls.

517 It can be concluded that the spores of L. muscarium can survive at low

518 temperatures $\left(15^{\circ} \mathrm{C}\right)$ and have the ability to start germination and infection after a few

519 days when they are placed at optimum temperatures between $20^{\circ} \mathrm{C}$ and $30^{\circ} \mathrm{C}$. Also, $M$.

520 persicae can be infected with $L$. muscarium by incubation at range of relative humidity

521 (55-90\%). Fungal infection does not have a physiological effect on the developing

522 progeny. However, the determination that L. muscarium had no significant impacts on

523 the daily reproduction of individual aphids. Based on these results, it is expected that

524 the commercially available mycoinsecticide Mycotal $^{\circledR}$, could be an appropriate

525 biological control agent and can be included in integrated pest management

526 programmes designed for controlling the populations of green peach aphids under the

527 field conditions during the summer season in the UK. However, frequent spraying may

528 be required to keep the aphid number lower than economic threshold level. Further

529 investigations on the impact of daily fluctuation in temperature through the day and

530 night hours and the potential impact of this entomopathogenic fungus on other

531 biocontrol agents, such as parasitoids and predators, will be required.

532 Acknowledgments

533 This research was funded by Ministry of Higher Education and Scientific Research in Iraq.

534 References

535 Abbott, W. S. (1925). A method of computing the effectiveness of an insecticide.

536 Journal of Economic Entomology, 18(2), 265-267.

537 Aiuchi, D., Saito, Y., Tone, J., Kanazawa, M., Tani, M., \& Koike, M. (2012). The effect

538 of entomopathogenic Lecanicillium spp.(Hypocreales: Cordycipitaceae) on the

539 aphid parasitoid Aphidius colemani (Hymenoptera: Aphidiinae). Applied

$540 \quad$ Entomology and Zoology, 47(4), 351-357. 
Al-Naemi, F., \& Hatcher, P. E. (2013). Contrasting effects of necrotrophic and biotrophic plant pathogens on the aphid Aphis fabae. Entomologia Experimentalis et Applicata, 148(3), 234-245.

Aqueel, M. A., \& Leather, S. R. (2013). Virulence of Verticillium lecanii (Z.) against cereal aphids; does timing of infection affect the performance of parasitoids and predators? Pest Management Science, 69(4), 493-498.

Ashouri, A., Arzanian, N., Askary, H., \& Rasoulian, G. (2003). Pathogenicity of the fungus, Verticillium lecanii, to the green peach aphid, Myzus persicae (Hom.: Aphididae). Communications in Agricultural and Applied Biological Sciences, 69(3), 205-209.

Askary, H., Carriere, Y., Belanger, R., \& Brodeur, J. (1998). Pathogenicity of the fungus Verticillium lecanii to aphids and powdery mildew. Biocontrol Science and Technology, 8(1), 23-32.

Åsman, K. (2007). Aphid infestation in field grown lettuce and biological control with entomopathogenic fungi (Deuteromycotina: Hyphomycetes). Biological Agriculture and Horticulture, 25(2), 153-173.

Baverstock, J., Roy, H., Clark, S., Alderson, P., \& Pell, J. (2006). Effect of fungal infection on the reproductive potential of aphids and their progeny. Journal of Invertebrate Pathology, 91(2), 136-139.

Blackman, R. L., \& Eastop, V. F. (2000). Aphids on the world's crop: an identification and information guide: Wiley, Chichester, United Kingdom.

Blackman, R. L., \& Eastop, V. F. (2008). Aphids on the world's herbaceous plants and shrubs: John Wiley \& Sons.

Blackman, R. L., \& Eastop, V. F. (2007). Insecticide Resistance. In H. F . Van Emden \& R. Harrington (Eds), Aphids as crop pests (pp. 1-22): CABI, Wallingford.

Climatological station. (2013). Weather in Reading [PDF]. Retrieved from http://www.met.reading.ac.uk/observatorymain/index.html

Cuthbertson, A. G., \& Walters, K. F. (2005). Pathogenicity of the entomopathogenic fungus, Lecanicillium muscarium, against the sweetpotato whitefly Bemisia tabaci under laboratory and glasshouse conditions. Mycopathologia, 160(4), 315-319.

Dedryver, C.-A., Le Ralec, A., \& Fabre, F. (2010). The conflicting relationships between aphids and men: a review of aphid damage and control strategies. Comptes Rendus Biologies, 333(6), 539-553. 
575 Diaz, B. M., \& Fereres, A. (2005). Life table and population parameters of Nasonovia ribisnigri (Homoptera: Aphididae) at different constant temperatures. Environmental Entomology, 34(3), 527-534.

Dixon, A. (1990). Population dynamics and abundance of deciduous tree-dwelling aphids. In A.D.Watt, S.R. Leather, M.D. Hunter and N.A.C. Kidd (Eds.), Population dynamics of forest insects (pp. 11-23). Intercept, Andover, Hampshire, UK.

Dixon, A. F. G. (2000). Insect predator-prey dynamics: ladybird beetles and biological control: Cambridge University Press.

Doberski, J. (1981). Comparative laboratory studies on three fungal pathogens of the elm bark beetle Scolytus scolytus: Effect of temperature and humidity on infection by Beauveria bassiana, Metarhizium anisopliae, and Paecilomyces farinosus. Journal of Invertebrate Pathology, 37(2), 195-200.

Fargues, J., Vidal, C., Smits, N., Rougier, M., Boulard, T., Mermier, M., Ridray, G. (2003). Climatic factors on entomopathogenic hyphomycetes infection of Trialeurodes vaporariorum (Homoptera: Aleyrodidae) in Mediterranean glasshouse tomato. Biological Control, 28(3), 320-331.

Faria, M. R. d., \& Wraight, S. P. (2007). Mycoinsecticides and mycoacaricides: a comprehensive list with worldwide coverage and international classification of formulation types. Biological Control, 43(3), 237-256.

Fatiha, L., Ali, S., Ren, S., \& Afzal, M. (2007). Biological characteristics and pathogenicity of Verticillium lecanii against Bemisia tabaci (Homoptera: Aleyrodidae) on eggplant. Pakistan Entomologist, 29(2), 63-72.

Feng, M. G., Poprawski, T., Nowierski, R., \& Zeng, Z. (1999). Infectivity of Pandora neoaphidis (Zygomycetes: Entomophthorales) to Acyrthosiphon pisum (Hom., Aphididae) in response to varying temperature and photoperiod regimes. Journal of Applied Entomology, 123(1), 29-35.

Ferron, P. (1977). Influence of relative humidity on the development of fungal infection caused by Beauveria bassiana (Fungi Imperfecti, Moniliales) in imagines of Acanthoscelides obtectus (Coleoptera: Bruchidae). Entomophaga, 22(4), 393396. 
Furlong, M. J., Pell, J. K., \& Reddy, G. (1997). Premortality effects of Zoophthora radicans infection in Plutella xylostella. Journal of Invertebrate Pathology, 70(3), 214-220.

Gurulingappa, P., McGee, P. A., \& Sword, G. (2011). Endophytic Lecanicillium lecanii and Beauveria bassiana reduce the survival and fecundity of Aphis gossypii following contact with conidia and secondary metabolites. Crop Protection, 30(3), 349-353.

Hall, R. (1982). A new insecticide against greenhouse aphids and whitefly: the fungus, Verticillium lecanii. Ohio Florists' Assoc Bull, 626, 3-4.

Hsiao, W. F., Bidochka, M., \& Khachatourians, G. (1992). Effect of temperature and relative humidity on the virulence of the entomopathogenic fungus, Verticillium lecanii, toward the oat-bird berry aphid, Rhopalosiphum padi (Hom., Aphididae). Journal of Applied Entomology, 114(1-5), 484-490.

Jeon, H. Y., Kang, T. J., Kim, H. H., Yang, C. Y., \& Kim, D. S. (2008). Economic injury level of Myzus persicae (Homoptera: Aphididae) at Chinese cabbage. Korean Journal of Applied Entomology, 47(4), 407-411.

Kim, J. J. (2007). Influence of Lecanicillium attenuatum on the development and reproduction of the cotton aphid, Aphis gossypii. BioControl, 52(6), 789-799.

Kim, J. J., Goettel, M. S., \& Gillespie, D. R. (2007). Potential of Lecanicillium species for dual microbial control of aphids and the cucumber powdery mildew fungus, Sphaerotheca fuliginea. Biological Control, 40(3), 327-332.

Kim, J. J., \& Roberts, D. W. (2012). The relationship between conidial dose, moulting and insect developmental stage on the susceptibility of cotton aphid, Aphis gossypii, to conidia of Lecanicillium attenuatum, an entomopathogenic fungus. Biocontrol Science and Technology, 22(3), 319-331.

Kindlmann, P., \& Dixon, A. (1989). Developmental constraints in the evolution of reproductive strategies: telescoping of generations in parthenogenetic aphids. Functional Ecology, 531-537.

Kirkland, B. H., Cho, E.-M., \& Keyhani, N. O. (2004). Differential susceptibility of Amblyomma maculatum and Amblyomma americanum (Acari: Ixodidea) to the entomopathogenic fungi Beauveria bassiana and Metarhizium anisopliae. Biological Control, 31(3), 414-421. 
Loureiro, E. d. S., \& Moino Jr, A. (2006). Pathogenicity of hyphomycet fungi to aphids Aphis gossypii Glover and Myzus persicae (Sulzer) (Hemiptera: Aphididae). Neotropical Entomology, 35(5), 660-665.

Miller, T., Gubler, W., Laemmlen, F., Geng, S., \& Rizzo, D. (2004). Potential for using Lecanicillium lecanii for suppression of strawberry powdery mildew. Biocontrol Science and Technology, 14(2), 215-220.

Milner, R., \& Lutton, G. (1986). Dependence of Verticillium lecanii (Fungi: Hyphomycetes) on high humidities for infection and sporulation using Myzus persicae (Homoptera: Aphididae) as host. Environmental Entomology, 15(2), 380-382.

Perdikis, D. C., Lykouressis, D. P., Garantonakis, N. G., \& Iatrou, S. A. (2004). Instar preference and parasitization of Aphis gossypii and Myzus persicae (Hemiptera: Aphididae) by the parasitoid Aphidius colemani (Hymenoptera: Aphidiidae). European Journal of Entomology, 101, 333-336.

Pianka, E. R. (2011). Evolutionary ecology. Population growth and regulation. $7^{\text {th }}$ edition-eBook. (pp. 135-176).

Poprawski, T. J., \& Jones, W. J. (2001). Host plant effects on activity of the mitosporic fungi Beauveria bassiana and Paecilomyces fumosoroseus against two populations of Bemisia whiteflies (Homoptera: Aleyrodidae). Mycopathologia, 151, 11-20.

Qayyum, A. (1999). Comparative behavioural studies on two closely related aphid parasitoids, Diaeretiella rapae (McIntosh) and Aphidius colemani (Viereck) sharing the same host species, Myzus persicae (Sulzer) (PhD thesis). University of Reading, Reading, UK.

Roditakis, E., Couzin, I. D., Franks, N. R., \& Charnley, A. K. (2008). Effects of Lecanicillium longisporum infection on the behaviour of the green peach aphid Myzus persicae. Journal of Insect Physiology, 54(1), 128-136.

Roy, H., Baverstock, J., Chamberlain, K., \& Pell, J. (2005). Do aphids infected with entomopathogenic fungi continue to produce and respond to alarm pheromone? Biocontrol Science and Technology, 15(8), 859-866.

Saljoqi, A. R. (2009). Population dynamics of Myzus persicae (Sulzer) and its associated natural enemies in spring potato crop, Peshawar, Pakistan. Sarhad Journal of Agricultural, 25(3), 451-456. 
Sharififard, M., Mossadegh, M., \& Vazirianzadeh, B. (2012). Effects of Temperature and Humidity on the Pathogenicity of the Entomopathogenic Fungi in Control of the House Fly, Musca domestica L.(Diptera: Muscidae) under Laboratory Conditions. Journal of Entomology, 9(5).

Shi, W. B., Feng, M. G., \& Liu, S. S. (2008). Sprays of emulsifiable Beauveria bassiana formulation are ovicidal towards Tetranychus urticae (Acari: Tetranychidae) at various regimes of temperature and humidity. Experimental and Applied Acarology, 46(1-4), 247-257.

Shrestha, G., Enkegaard, A., \& Steenberg, T. (2015). Laboratory and semi-field evaluation of Beauveria bassiana (Ascomycota: Hypocreales) against the lettuce aphid, Nasonovia ribisnigri (Hemiptera: Aphididae). Biological Control, 85, 37 45.

Sikura, A., Sikura, L., \& Trebesava, R. (1972). Influence of white muscardine fungus (Beauveria bassiana Balsamo Vuillemin) on the reproductive system of the Colorado potato beetle. Zashch. Rast. Kichinev, 2, 89-97. (In Russian)

Sukhova, T. (1987). The biological method in the greenhouse. Zashchita Rastenii, 2 , 37-38.

Tang, L. C., \& Hou, R. F. (1998). Potential application of the entomopathogenic fungus, Nomuraea rileyi, for control of the corn earworm, Helicoverpa armigera. Entomologia Experimentalis et Applicata, 88(1), 25-30.

Vu, V. H., Hong, S. I., \& Kim, K. (2007). Selection of entomopathogenic fungi for aphid control. Journal of Bioscience and Bioengineering, 104(6), 498-505.

Wang, Z., \& Knudsen, G. (1993). Effect of Beauveria bassiana (Fungi: Hyphomycetes) on fecundity of the Russian wheat aphid (Homoptera: Aphididae). Environmental Entomology, 22(4), 874-878.

Wekesa, V., Knapp, M., Maniania, N., \& Boga, H. (2006). Effects of Beauveria bassiana and Metarhizium anisopliae on mortality, fecundity and egg fertility of Tetranychus evansi. Journal of Applied Entomology, 130(3), 155-159.

Willmer, P. (1986). Microclimatic effects on insects at the plant surface. In B. Juniper, $\&$ T.R.E. Southwood (Eds), Insects and the plant surface (pp. 65-80). Edward Arnold, London.

Wraight, S., Carruthers, R., Jaronski, S., Bradley, C., Garza, C., \& Galaini-Wraight, S. (2000). Evaluation of the entomopathogenic fungi Beauveria bassiana and 
Paecilomyces fumosoroseus for microbial control of the silverleaf whitefly, Bemisia argentifolii. Biological Control, 17(3), 203-217.

Xu, J. H., \& Feng, M. G. (2002). Pandora delphacis (Entomophthorales: Entomophthoraceae) infection affects the fecundity and population dynamics of Myzus persicae (Homoptera: Aphididae) at varying regimes of temperature and relative humidity in the laboratory. Biological Control, 25(1), 85-91.

Yeo, H., Pell, J. K., Alderson, P. G., Clark, S. J., \& Pye, B. J. (2003). Laboratory evaluation of temperature effects on the germination and growth of entomopathogenic fungi and on their pathogenicity to two aphid species. Pest Management Science, 59(2), 156-165.

Table 1 Repeated measures analysis of variance of the effect of L. muscarium application on the population growth of M. persicae on Brussels sprouts and shoot dry weight of aphid-infested plants.

\begin{tabular}{|l|l|l|l|}
\hline Source & \multirow{2}{*}{ DF } & SS \\
\cline { 3 - 4 } & & Aphid population & Dry weight of plant \\
\hline Spore dosage & 2 & $6.902 * * *$ & $6.794 * *$ \\
\hline Time after treatment & 3 & $27.051 * * *$ & $10.376^{* *}$ \\
\hline Spore dosage $*$ Time & 6 & $0.282^{* * *}$ & 0.994 \\
\hline Residual & & & 39.040 \\
\hline
\end{tabular}




\begin{tabular}{|l|l|l|l|}
\hline Total & 95 & 34.799 & 67.787 \\
\hline$* * * P \leq 0.001 ; * * P \leq 0.05$. & & \\
\hline
\end{tabular}

730

731 Table 2 Population growth rate of exposed aphids during the time after application

732 compared to unexposed aphids.

\begin{tabular}{|c|c|c|c|}
\hline \multirow[t]{2}{*}{$\begin{array}{l}\text { Treatment } \\
\text { (viable spore } / \mathrm{mm}^{2} \text { ) }\end{array}$} & \multicolumn{3}{|c|}{$\begin{array}{l}\text { Population growth rate }(\%) \text { during the weeks after } \\
\text { application }\end{array}$} \\
\hline & Week 2-3 & Week 3-4 & Week 4-5 \\
\hline Dosage $(644 \pm 50)$ & $121.7 \pm 26.7 b$ & $309 \pm 18.6 c$ & $83.7 \pm 13.9 \mathrm{a}$ \\
\hline Dosage $(330 \pm 40)$ & $447.2 \pm 23.9 \mathrm{a}$ & $668 \pm 23 c$ & $620.3 \pm 41.6 b$ \\
\hline Control & $618 \pm 37.7 a$ & $925.2 \pm 42.5 b$ & $949.6 \pm 42.2 \mathrm{c}$ \\
\hline
\end{tabular}

Means followed by different letter(s) in each column are significantly different at $P<$

$734 \quad 0.05$, using LSD test.

\section{Figure legends}

Figure 1 The effect of relative humidity, spore dosage and days after fungal application on the corrected mortalities (mean $\pm \mathrm{SE}, \mathrm{n}=5$ ) of $M$. persicae treated with L. muscarium after 2 days incubation at either 55,70 or $90 \%$ RH and then 8 days at $70 \%$ RH. High, medium and low dosages were $880 \pm 32,664 \pm 50$ and $330 \pm 40$ viable spore $/ \mathrm{mm}^{2}$. Figure 2 The effect of relative humidity, spore dosage and days after fungal application on the cumulative mortalities $( \pm \mathrm{SE})$ of M. persicae treated with L. muscarium after 2 days incubation at either 55,70 or $90 \%$ RH and then 8 days at $55 \%$ RH. High, medium and low dosages were $880 \pm 32,664 \pm 50$ and $330 \pm 40$ viable spore $/ \mathrm{mm}^{2}$. 
747 Figure 3 The effect of temperature, spore dosage and period of time after application on the corrected mortalities (mean $\pm \mathrm{SE}, \mathrm{n}=5$ ) of $M$. persicae treated with $L$. muscarium after 10 days incubation at $15,20,25$ or $30^{\circ} \mathrm{C}$. High, medium and low dosages were 880 $\pm 32,664 \pm 50$ and $330 \pm 40$ viable spore $/ \mathrm{mm}^{2}$.

751 Figure 4 The effect of temperature, spore dosage and period of time after application on

752 the corrected mortalities (mean $\pm \mathrm{SE} ; \mathrm{n}=5$ ) of $M$. persicae treated with L. muscarium

753 after 3 days incubation at either $15,20,25$ or $30^{\circ} \mathrm{C}$ and then 7 days at $20^{\circ} \mathrm{C}$. High,

754 medium and low dosages were $880 \pm 32,664 \pm 50$ and $330 \pm 40$ viable spore $/ \mathrm{mm}^{2}$.

755 Figure 5 Corrected mortality $( \pm$ SE; $n=10)$ of first, third and fourth instar nymphs and 756 adults of M. persicae sprayed with different spore dosages of L. muscarium. High, 757 medium and low dosages were $880 \pm 32,664 \pm 50$ and $330 \pm 40$ viable spore $/ \mathrm{mm}^{2}$.

758 Figure 6 Effect of fungal infection on the mean numbers of nymphs produced per aphid 759 per day, mean length of reproductive period and mean fecundity of $M$. persicae after treatment with two spore dosages of L. muscarium at either adult, $3^{\text {rd }}$ instar nymph or $1^{\text {st }}$ instar nymphs, compared to the control. Different letters above columns indicate significant differences in the values at $P<0.05$, using LSD test. Medium and low dosages were $664 \pm 50$ and $330 \pm 40$ viable spore $/ \mathrm{mm}^{2}$.

764 Figure 7 The effect of L. muscarium application on (A) the population growth of $M$. 765 persicae (mean $\pm \mathrm{SE} ; \mathrm{n}=8$ ) and $(\mathrm{B})$ shoot dry weight of aphid-infested plants (mean \pm 766 SE; $\mathrm{n}=8$ ) compared with the control treatment. Medium and low dosages were $664 \pm$ 767 50 and $330 \pm 40$ viable spore $/ \mathrm{mm}^{2}$. 

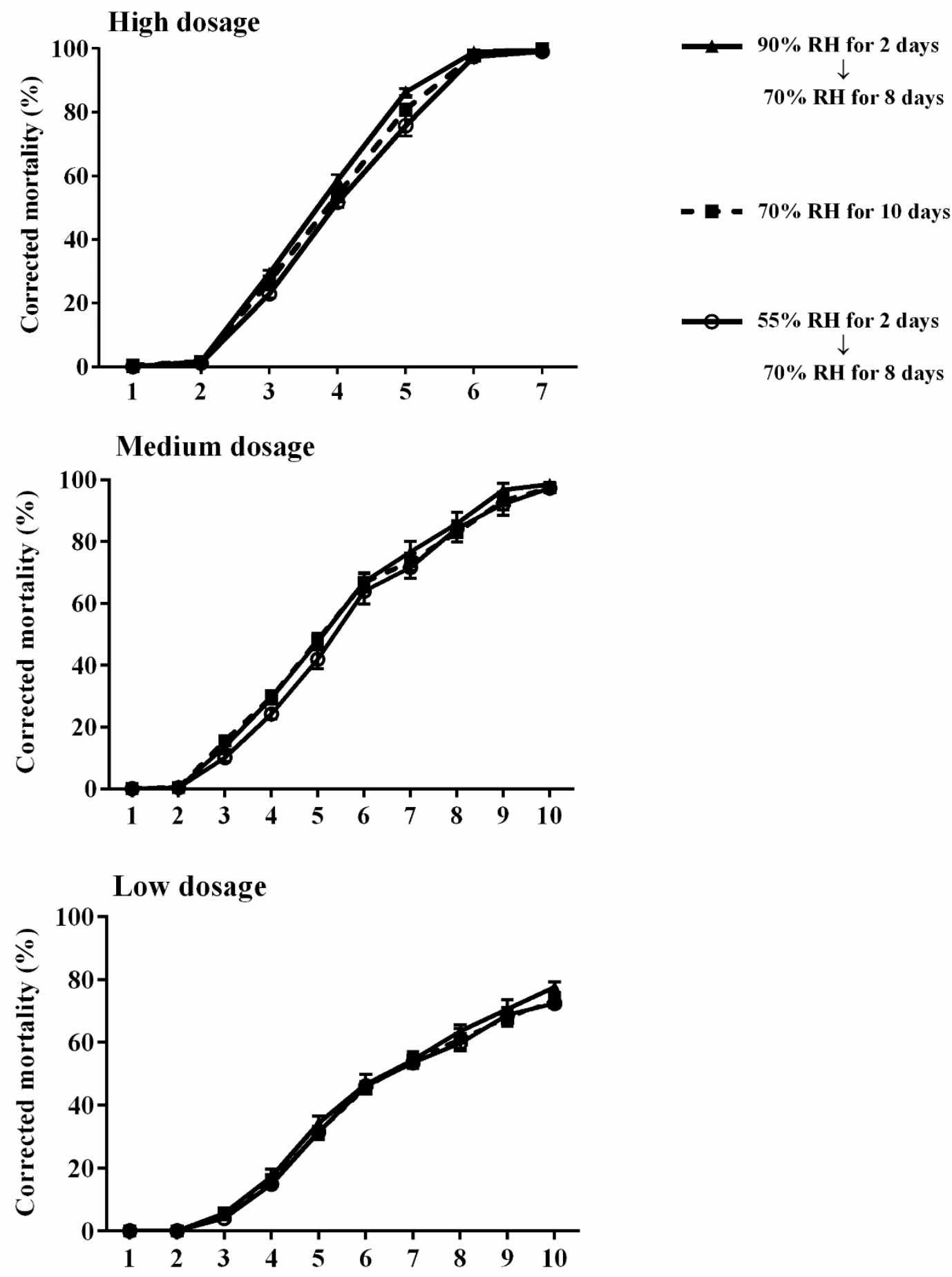

Days after fungal application 

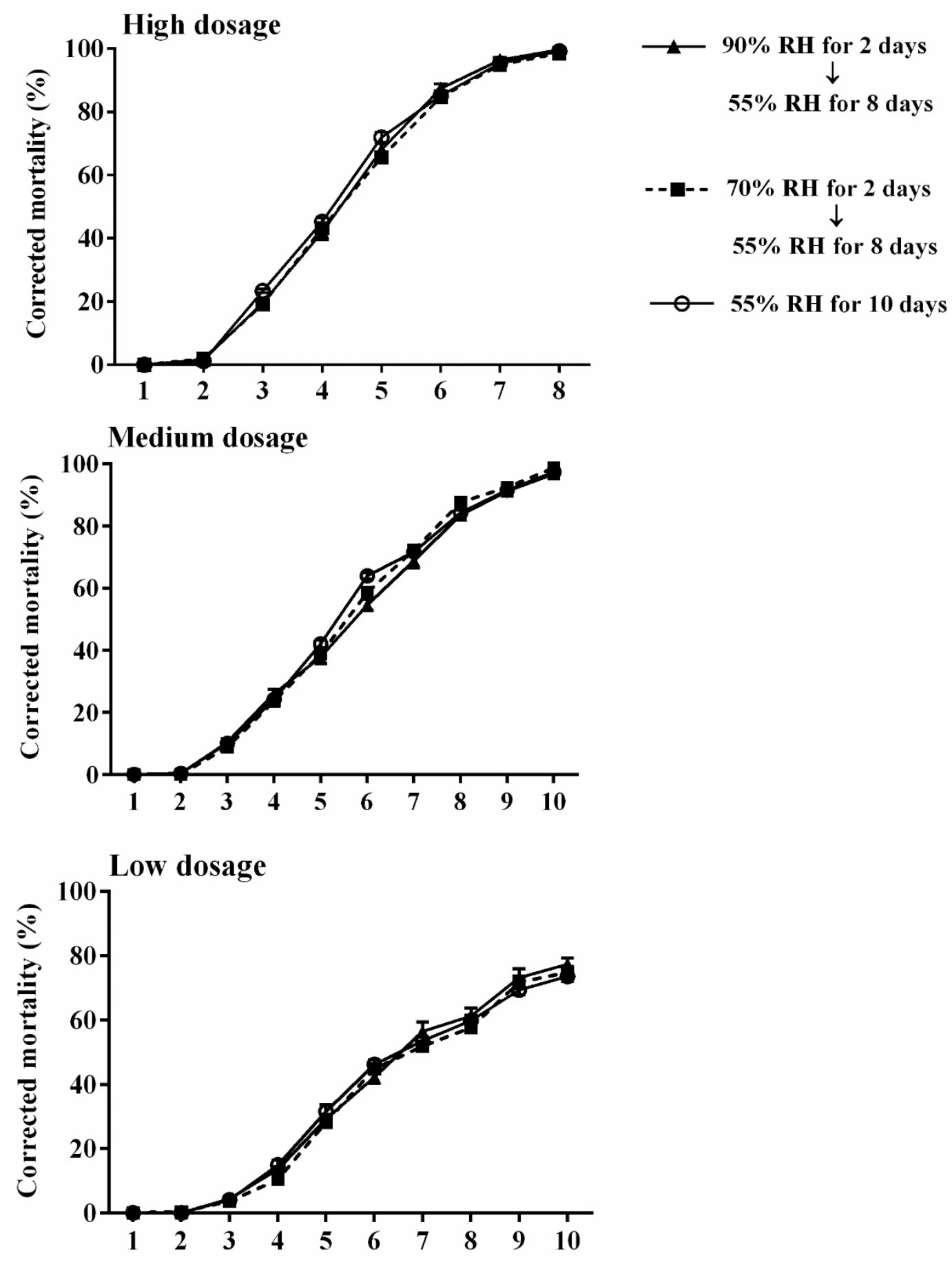

Days after fungal application 

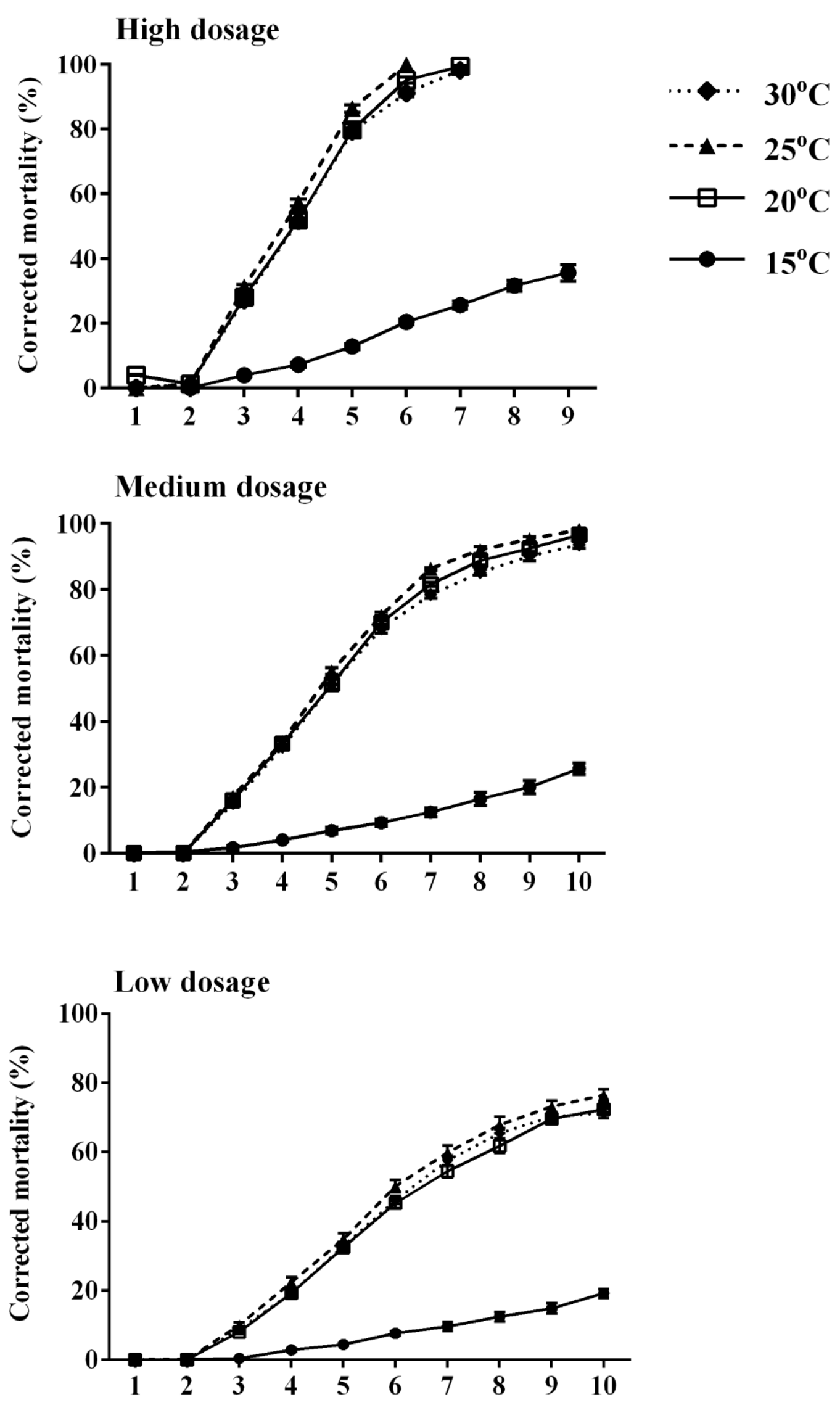

Days after fungal application 

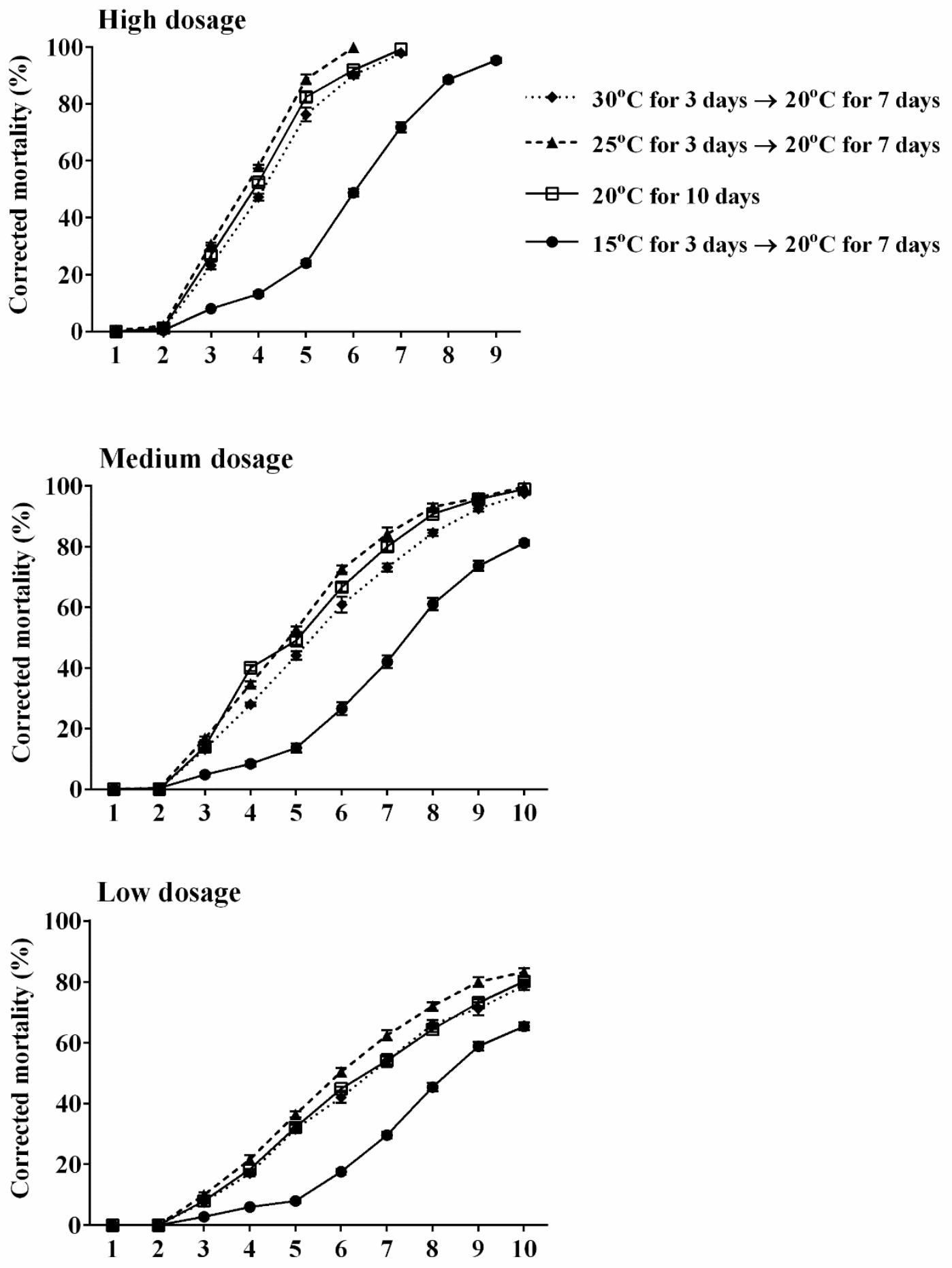

Days after fungal application 

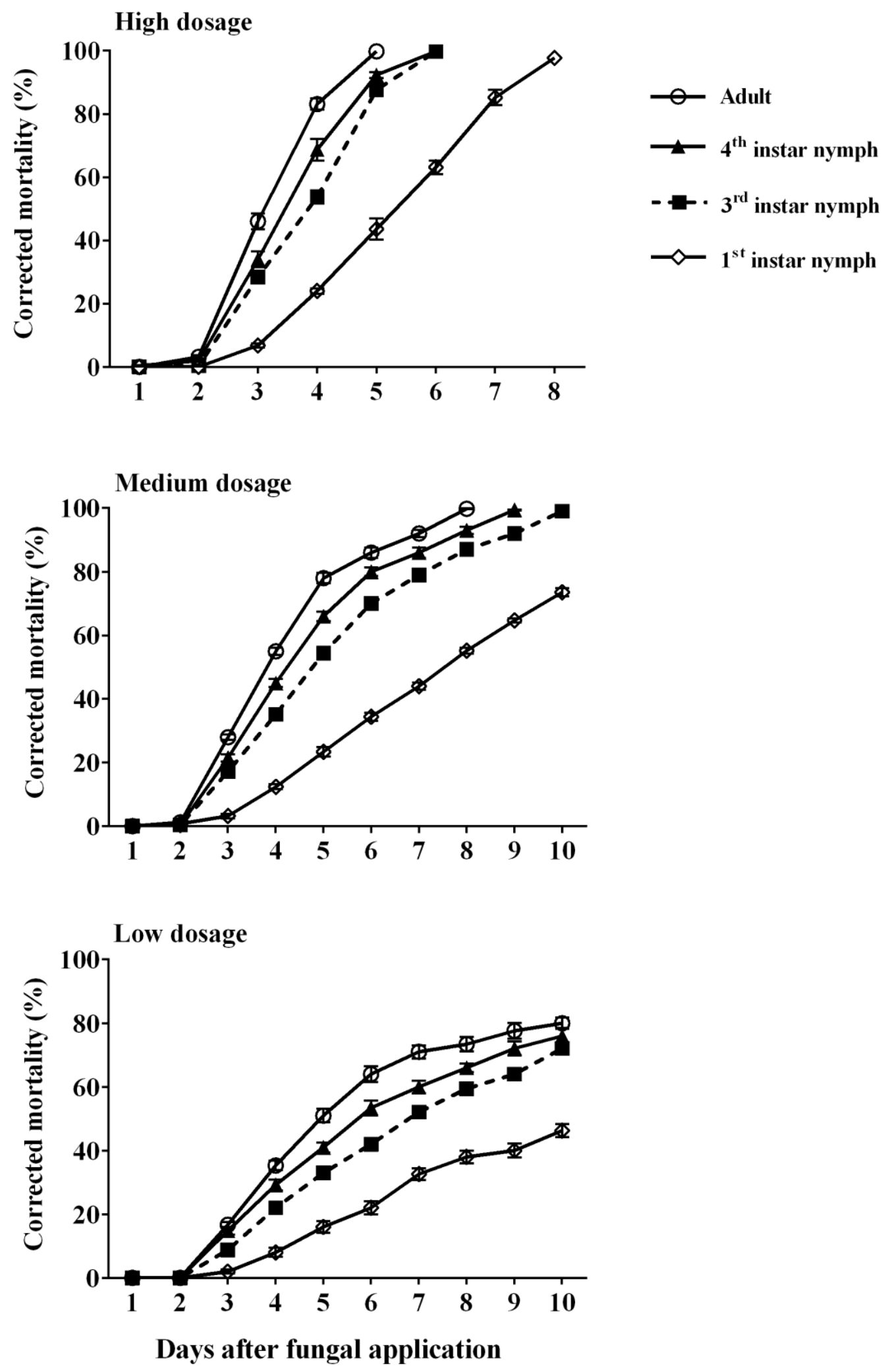

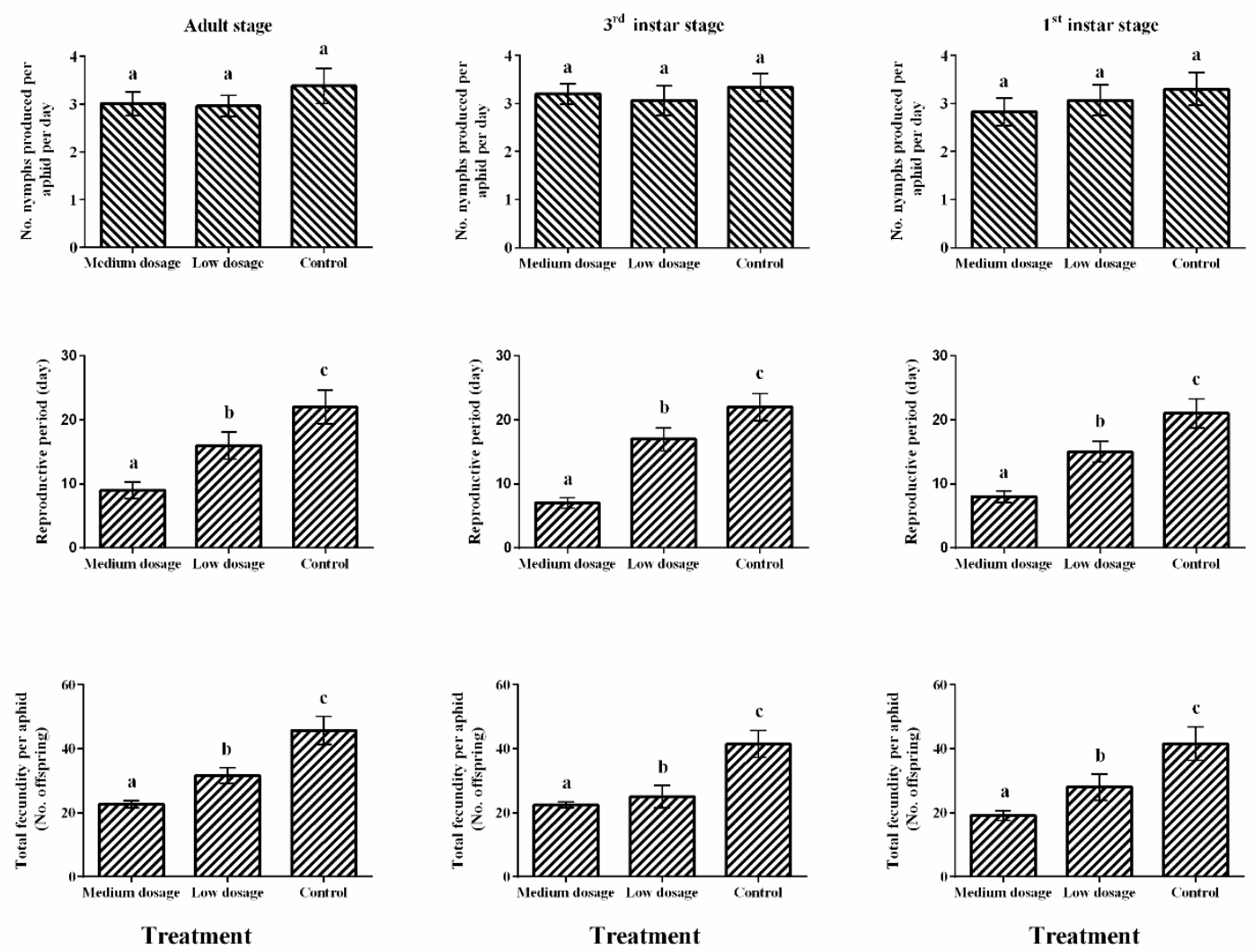


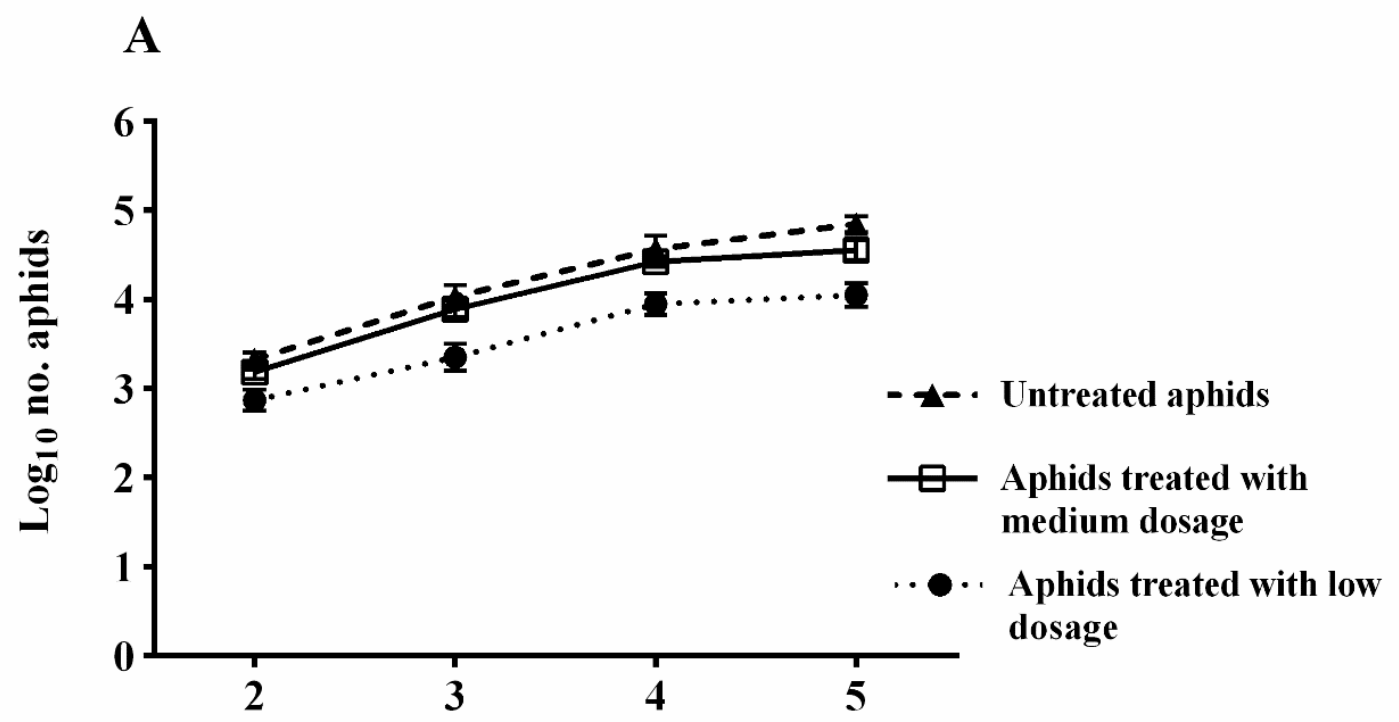

B

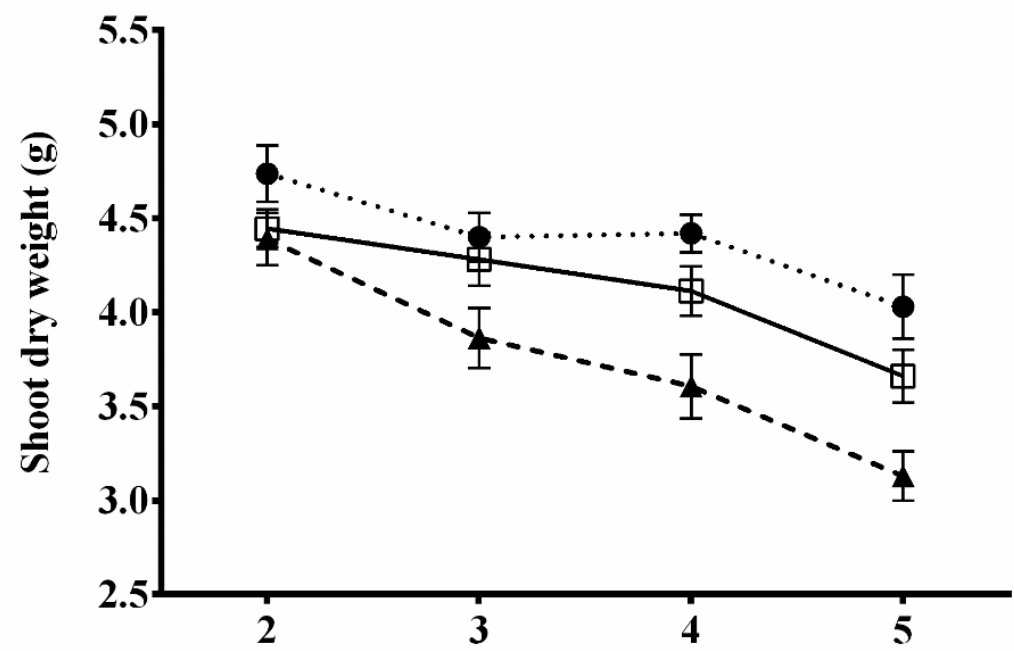

Weeks after fungal application 